UDC: 582.929.4-113.5:615.281.942.14

DOI: 10.33320/maced.pharm.bull.2020.66.03.003

\title{
In vitro antimicrobial properties of basil and thyme essential oils against Salmonella Spp.
}

\author{
Metodija Trajchev ${ }^{1} *$, Jasmina Stojiljkovic ${ }^{2}$, Dimitar Nakov ${ }^{1}$, Marija Glavash Dodov $^{3}$, \\ Milena Petrovska ${ }^{4}$ \\ ${ }^{I}$ Faculty of Agricultural Sciences and Food, Ss. Cyril and Methodius University, \\ Blvd. Aleksandar Makedonski bb, 1000 Skopje, North Macedonia \\ ${ }^{2}$ College of Applied Studies, Filip Filipovic 20, 17500 Vranje, Republic of Serbia \\ ${ }^{3}$ Faculty of pharmacy, Ss. Cyril and Methodius University, Majka Tereza 47, 1000 Skopje, North Macedonia \\ ${ }^{4}$ Faculty of medicine, Ss. Cyril and Methodius University, 50 Divizija 6, 1000 Skopje, North Macedonia
}

\section{Introduction}

Food diseases are caused by consuming foods that have been contaminated by an infectious agent or a toxin produced by it. According to the WHO, $30 \%$ of people in industrialized countries suffer from foodborne diseases. Salmonella enteritidis even at $95.9 \%$ was the main etiological factor for salmonellosis in humans (De Knegt et al., 2015) and have established a trend of increasing the level of contamination of food products with Salmonella spp. in the Republic of North Macedonia. In order to protect food from contamination with pathogens and other harmful microorganisms, many scientists have examined the antifungal, antibacterial and antioxidative properties of essential oils (EOs) and their application in food technology. They are considered a safe and environmentally friendly alternative to the control of bacteria present in the food and food industry, but also to the control of other pathogenic microorganisms, especially those that are drug resistant (Yap et al., 2014).

The aim of the study was to determine the antimicrobial effect of different concentrations of basil and thyme EOs on the growth of Salmonella enteritidis in laboratory conditions, inoculated in dough for making pasta with eggs and inoculums with flour and chicken egg.

\section{Materials and Methods}

All samples were prepared in duplicate. The test samples were prepared as micellar solution from basil and thyme EOs in physiological solution $(\mathrm{PhS})$ up to final concentration of $1,2.5$ and $5 \%$, as well as $\mathrm{PhS}$ without EOs as a control. The first group of test samples were prepared from $25 \mathrm{~g}$ of the dough used for preparation of the egg-based pasta, inoculated with $0.1 \mathrm{~mL}$ of the suspension of Salmonella enteritidis with the initial number of bacteria from $10^{9} \mathrm{CFU} / \mathrm{g}$. After inoculation, the micellar solutions of basil and thyme EOs were added to the prepared dough. A quantity of $25 \mathrm{~g}$ of dough was mixed with $225 \mathrm{~mL}$ of selenite $\mathrm{F}$ broth and incubated for $24 \mathrm{~h}$ at $37{ }^{\circ} \mathrm{C}$.

The second group of test samples was prepared as a mixture of flour and a mixture of egg with the micellar solutions of basil and thyme EOs. Afterwards, the samples were inoculated with Salmonella enteritidis. The ready suspension from Salmonella enteritidis have been inoculated in $5 \mathrm{~mL}$ of the micellar solutions of basil and thyme EOs as well as $5 \mathrm{~mL}$ of $\mathrm{PhS}$ (control), in initial

\footnotetext{
*metot@fznh.ukim.edu.mk
} 
concentration of bacteria from $10^{9} \mathrm{CFU} / \mathrm{mL}$. In the samples, $90 \mathrm{ml}$ of Salenit $\mathrm{F}$ broth were added and duplicate samples were incubated at two regimes: one sample for $9 \mathrm{~h}$ at $46^{\circ} \mathrm{C}$ and the other one for 18 h at $37{ }^{\circ} \mathrm{C}$. Dilutions 1:20 and 1: 200 were prepared from all samples and from them $0.1 \mathrm{~mL}$ was inoculated on Müller-Hinton agar, for enumeration of bacterial cell count (CFU). Petri plates were incubated at $37^{\circ} \mathrm{C}$ for 18 hours (ISO 6579-1, 2017). Data analysis was carried out with GLM-General Linear Model.

\section{Results and discussion}

Foods of animal origin, especially poultry and poultry products, including eggs, have been consistently implicated in sporadic cases and outbreaks of human salmonellosis (FAO/WHO, 2002). Hence, the use of plant EOs as a substitute for synthetic antimicrobials is of great importance as most of them have proven efficacy in the control of bacteria present in the food and food industry.

Related to the results from the research, the $\log _{10}$ number of bacterial cells of Salmonella enteritidis was gradually decreased in each successive concentration of basil and thyme EOs. In the samples of pasta dough with micellar solution of basil EOs, the CFU of $S$. enteritidis showed a trend of decreasing from the samples without added EOs to the samples with added $5 \%$ of basil EOs, ranged from $8.46 \pm 0.071$ to $8.04 \pm 0.113 \log _{10} \mathrm{CFU} / \mathrm{mL}$. In the samples of dough with micellar solution of thyme EOs, the decreasing ranged from $8.24 \pm 0.075$ to $7.29 \pm 0.142 \log _{10} \mathrm{CFU} / \mathrm{mL}$. The same trend was established also in the samples with a mixture of flour and homogenized egg. The decreasing in the $\log _{10} \mathrm{CFU} / \mathrm{mL}$ of Salmonella enteritidis in the samples with added basil EOs was ranged from $5.69 \pm 0.700$ to $3.08 \pm 0.805$; while in the samples with thyme EOs from $5.72 \pm 0.064$ to $1.84 \pm 0.784 \log _{10}$ $\mathrm{CFU} / \mathrm{mL}$ Salmonella enteritidis, respectively. Overall, in all samples the trend of decreasing in the $\log _{10}$ number of Salmonella enteritidis from control samples to the samples with added 5\% EOs ranged from $7.77 \pm 0.184$ to $5.93 \pm 0.407 \log _{10} \mathrm{CFU} / \mathrm{mL}$. The GLM statistical model showed that the $\log _{10}$ number of bacterial cells of Salmonella enteritidis was statistically significant influenced by the added EOs $(\mathrm{F}=4.171 ; \mathrm{df}=1 ; \mathrm{p}<0.05)$ and their concentration $(\mathrm{F}=$ 4.879; $\mathrm{df}=3 ; \mathrm{p}<0.01$ ), while their interaction didn't show statistically significant influence $(\mathrm{F}=0.350$; $\mathrm{df}=3$ ) on Salmonella enteritidis $\log _{10} \mathrm{CFU} / \mathrm{mL}$.
Herewith, the findings of some authors suggest that the reason for the weaker antimicrobial effect of plant EOs, is the interaction that have essential oils and bacteria with the food ingredients (Hayouni et al., 2008). It has been found that in order to obtain the optimal antibacterial effect in the food, it is necessary to use several times higher concentration of EOs of plants than the laboratory determined concentration (de Oliveira et al., 2013).

\section{Conclusion}

The basil and thyme EOs as natural preservative might be useful in the control of Salmonella spp. in food like pasta, prepared from white flour and eggs, as an alternative of the chemical preservatives.

\section{References}

De Knegt, L.V., Pires, S.M., Hald, T., 2015. Attributing foodborne salmonellosis in humans to animal reservoirs in the European Union using a multicountry stochastic model. Epidemiol. Infect. 143, 1175-1186.

De Oliveira, T.L.C., de Araújo Soares, R., Piccoli, R. H., 2013. A Weibull model to describe antimicrobial kinetics of oregano and lemongrass essential oils against Salmonella Enteritidis in ground beef during refrigerated storage. Meat Science 93(3), 645-651.

FAO/WHO, 2002. Microbiological risk assessment series No. 2. Risk assessments of Salmonella in eggs and broiler chickens.

Hayouni, E.A., Chraief, I., Abedrabba, M., Bouix, M., Leveau, J.Y., Mohammed, H., Hamdi, M., 2008. Tunisian Salvia officinalis L. and Schinus molle L. essential oils: Their chemical compositions and their preservative effects against Salmonella inoculated in minced beef meat. Int. J. Food Microbiol. 125, 242251.

ISO 6579-1, 2017. Microbiology of food and animal feedingstuffs - Horizontal method for the detection of Salmonella spp. in the food production chain. Geneva, Switzerland.

Yap, P.S.X., Yiap, B.C., Ping, H.C., Lim, S.H.E., 2014. Essential oils, a new horizon incombating bacterial antibiotic resistance. Open Microbiol. J. 8, 6-14. 